\title{
THE GEOGRAPHY OF MONEY \\ REGIONAL - GEOGRAPHIC CONCENTRATION \\ AND FUNCTIONALITY OF THE MONEY IN THE WORLD
}

DOI: http://dx.doi.org/10.18509/GBP.2015.65

UDC: 911.336.74(100)

\author{
Blagoja Markoski, PhD \\ University "Ss. Cyril and Methodius ", Faculty of Natural Sciences and Mathemathics, \\ Institute of Geography - Skopje
}

\begin{abstract}
It is generally known that Geography is the science of studying the Earth. Earth as a celestial body is very complex physical-geographic, socio-geographic, economic, geographical, socio-political, infrastructural, functional, etc. system. Because Geography contains many scientific disciplines that study the various segments of this complex system. They developed a large variety of geographies. But the problem of geographical distribution and functionality of money as means that direct dependence of the regional development in the world, however, they are not are not specifically addressed. That is why the problem of the research in this article is positioned and regional concentration (distribution) as well as the functionality of money.

Furthermore, it is a regional review of the developed countries in the world, the regional concentration of the world's population, the problem of so-called active and passive money, the influence of money on the development of the regions, inactivated money, spill over of money, possible consequences of extremely uneven distribution of money in the world, etc.

The article aims to initiate a need of establishing new geographical science which will be called the Geography of Money, Bank Geography, Monetary Geography or otherwise. In this case, I have chosen the term Geography of Money, but honestly I do expect other views and analyses of this phenomenon.
\end{abstract}

Key words: Geography, money, geographic concentration of money, geographic active and passive money

\section{INSTEAD OF INTRODUCTION}

Geography is science that studies the Earth. In the early development of geographical science was aimed at providing introduction of the immediate surroundings, then it was oriented towards discovering the most remote areas of the given point. With great geographical discoveries directly proved the spherical form of the Earth. Later, Australia and Polar Regions and numerous small island territories were discovered. Therefore to sum up the image of the Earth as a planet, the notion of land and water surfaces.

In addition, geographical science aims to regional identification of territories. In this way, were determined the continents, oceans and numerous specific regions within them.

The challenge is continued by studying the characteristics of relief, climate, water and wildlife. The results were amazing, with great geographical diversity. Due to it was found different position of the man in space. Thus the general identification of ecumenical and 
oecumenical space of the Earth subtle approaches to the study of population, its distribution, natural development, dynamics and migrations.

It allowed special treatment and the occurrence of anthropogeography i.e. geography of population and settlements.

In the race for providing better living conditions through technological progress will inevitably appear the need for geographical treatment of the condition and density of economic capacities and facilities. Closely associated with them, geographic studies of numerous non-economic activities and industries appeared as an important factor for change in the geographical space. This has resulted in the appearance of Economic Geography within which developed greater number of specific and targeted scientific disciplines, such as Agrarian Geography, Industrial Geography, Tourism Geography, Traffic Geography, Military Geography, Forestry Geography, Geography of Natural Resources, Geography of Energetics, Medical Geography, etc. Therefore a lot of scientific disciplines as an object of study have a certain segment of commercial and noncommercial activities.

In the context of this approach, there has not been given more consistent attention to the concentration of money or banking yet. Surely, it is because a general belief that money is purely economic issue, no concrete relationship and influence with geospatial and so similar. However, the attractive power of money has a big impact on the geographical changes in the geographical space [5]. Money influence like the attractive force of (mines generally) gold mines as examples of the geographical changes on the western coast of Australia due to the larger number of gold mines.

Considering the massive use of money in societies, referring the huge changes in the geographical space made by money and for money seriously question the need for setting thoughts and forming a new scientific discipline within which economic geography as a subject of the study will have the geographical distribution and concentration of money [4] natural and anthropogenic values.

\section{REGIONAL CONCENTRATION OF WORLD POPULATION}

Most of the Earth is oecumenical. The areas considered ecumene (inhabited space or spaces where people can live undisturbed) are smaller. Within the ecumenical space, due to various relief, hydrographic and climatic reasons, the population is concentrated in certain regions. Namely, the world as densely populated regions are separated Western Europe, Gang-Bengal Lowland, East Asian lowlands, South-eastern Asia, the valleys of the Tigris and Euphrates rivers, coastal areas of Egypt, coastal parts of Morocco and Algeria, Nigeria, South Africa Republic, Kenya and Tanzania, the east coast of the United States, around the Great Lakes Region in the North America, California, the east coast of Brazil and Argentina (around the Bay of La Plata and Rio de Janeiro), Southeast parts of Australia [6].

These mentioned regions are densely populated (at least more than $100 \mathrm{~g} / \mathrm{km}^{2}$ ), but not all economically developed. 
Fig. 1. Density of population in the world

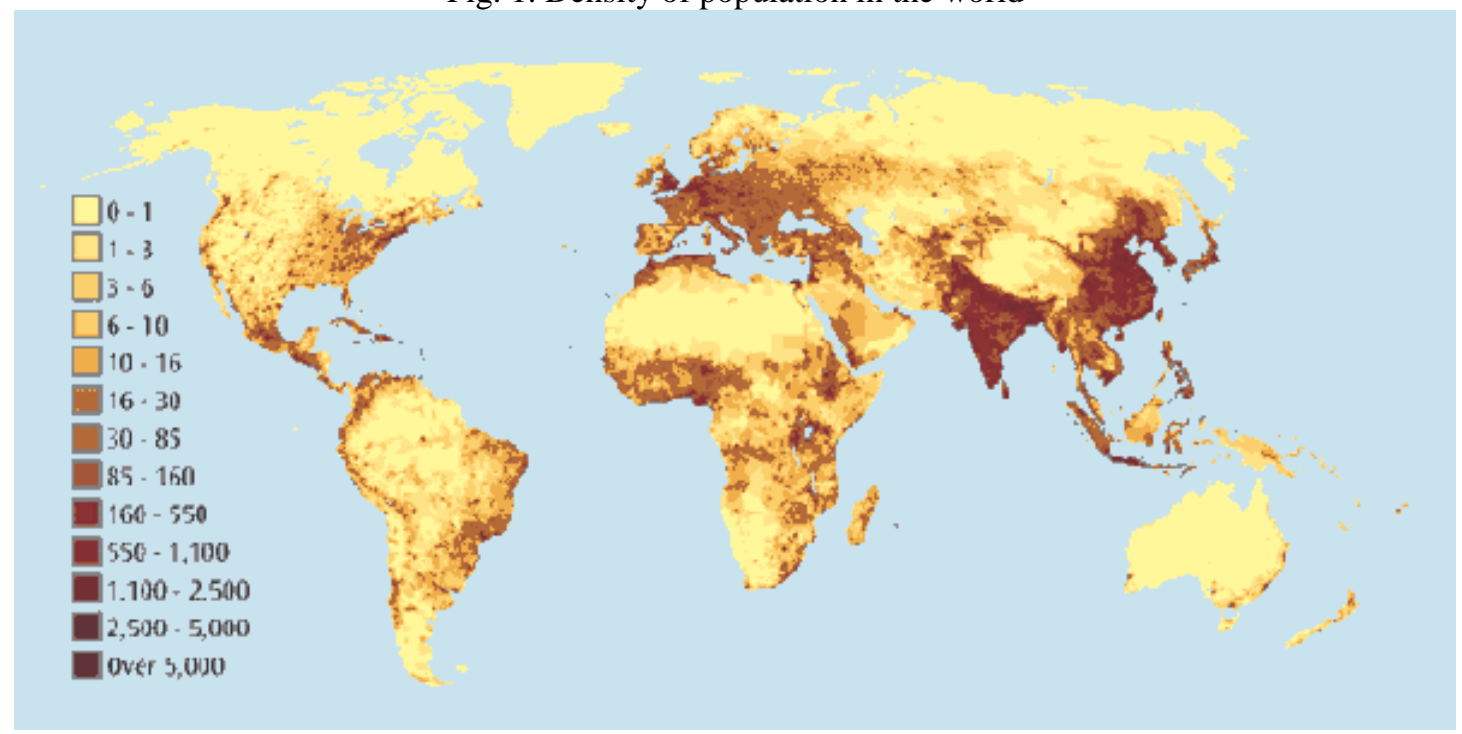

Source: http://modernsurvivalblog.com/retreat-living/survival-retreat-population-density/ [6]

\section{REGIONAL OVERVIEW OF DEVELOPING AREAS IN THE WORLD}

Strong economic developed regions in Western Europe, Central Europe, Russia and North Europe, Atlantic Plain in the USA, the region around the Great Lakes in North America, South Africa, Japan, Taiwan, South Korea and South-eastern parts of Australia. They are regions with a large population and a large financial capital where in addition to the regions themselves invest in other regions (mostly in regions rich in raw and regions with cheap work force and) so that capital quickly multiplies.

There are regions that are highly developed but there is not a large number of people. They do the same but their power is significantly lower in the geographical area e.g. Norway, Sweden and so on.

As the third positioned are those regions where the population is relatively less presence, but because natural resources those regions have large financial resources. Those are the regions of Southwest and Central Asia, Northern and North-western parts of South America. But these regions often neglect investments in other regions. The reasons are secure in the fact that on one hand the natural resources in these regions largely managed by foreign multinationals and on the other hand the culture and tradition of domestic owners of wealth in these countries not-oriented investment and development in other regions of the world. Maybe if someone dares to finance outside their country they do in non-manufacturing industries such as traffic, tourism or sport on the basis of sponsorship and similar to the previously mentioned [5].

\section{ACTIVE AND PASSIVE MONEY}

The term active money in this case ,the use of financial resources or those in circulation motion, investment in various sectors, getting profit and extra profit, perform various transactions in order for fertilization of capital and achieving greater growth and development of the regions. This process there is overflow capital from one region to another.

Typical examples of active capital are highly developed countries where the money is imperative to constantly being in circulation at work, because this is the best way to be fertilized. Precisely because of this group of countries are about to invest in other regions, 
rich in various resources and a cheap labour force on the other side so that profit is always very high.

Despite exploratory approach, and also the region, which is somehow exploited, has its own economic growth and development therefore obtains different geographical characteristics [5]. All this is due to active money.

In this case the term passive money is used for the funds that are earned, saved and collected as wealth increases only on the basis of interest rates (much less) than lending money that is constantly in circulation and more profitable significantly. Therefore, free to conclude that the passive money has less influence in the geographical space. Typical examples of passive money countries in southwest Asia, part of North Africa and the countries of northern and north-western parts of South America, which are characterized by piling up treasures in a small circle of people who cannot or do not enter the process of moving and fertilization capital.

\section{INFLUENCE OF MONEY ON DEVELOPMENT OF REGIONS}

In every human activity one of the development factors is the capital or money as a development factor. However, the early development of many regions of the world rather based on intuition, innovation, initiative, knowledge and desire of nature on Earth to produce (products which continues through the process of getting money exchange), cash and much more than then amount of invested capital. Through the efforts of people in the Ruhr and Saar, the Appalachian Mountains and Atlantic Plain in the United States, Japan and other regions, the low capital has been fertilized today on that rate, the previously mentioned and other similar regions are characterized by such a high level of growth and development. Their influence through investment has reflected today in various other regions, precisely because the number and location of highly developed regions are increasing. As an example for the highly developed such as regions of Europe, Atlantic Plain in the United States, California, Japan joined the regions of South Africa, South Korea, Eastern China, Turkey, South Australia, parts of India, etc. [5].

Certainly for their development, a major impact has the capital or money, but it must be emphasized that the development of the region is closely dependent on knowledge, innovation, initiative and the organization of society and work in each specific activity. In the context of the enormous population growth in some regions of the world, the organization of society and work will be inevitable because the developed world will not be able to achieve to invest their money (figuratively speaking)for interests of other parties.

\section{REGIONAL OVERFLOW OF CAPITAL}

The overflow of capital is a broad issue which has been being elaborated in the economy, since it is one of the basics how and where the capital to be directed as well as how to outwit the other party. This is a problem in the relationship among economic subjects, but realistically growing processes of globalization overflow of the capital gets geographic dimensions as well, whereas it overflow, states and whole regions receive enormous geographical changes, either in a positive or in a negative sense.

Positive aspects are mainly seen in the countries where investments are made by other countries or international institutions. So part of the capital Therefore there is pouring of the capital into so called less developed countries or regions. The positive aspect is that an underdeveloped country or region will advance in its development, that is to say will gain greater growth. Whether is it reflected in reality? Everyone was happy that there 
were certain investments, new jobs were available, and there would be higher salaries than the current ones in a particular society (state). Almost no one (there are individual exceptions) do analyses based on real exploitation of clean raw material, cheap labour, almost no transportation costs for raw materials etc. Therefore low capital is invested and a profit and extra profit is made from so called undeveloped areas actually overflowing in developed regions and to a much greater extent than the initial investment. It is unbelievable but it is true. [5]

There are many similar and even more sophisticated ways overflow of capital, simply a person cannot enumerate them. For instance, the agriculture both in Tanzania and Macedonia where the whole harvest or more harvests have to be sold in order a machine to be bought.

In the context of this when outwitting of the developed countries in this area came to an end, they are directed to other worlds and regions, appearing as their saviours.

Proposing new approaches in the educational system, where under the guise of practical education destroy national education systems, and thus their own technical and technological development. They buy the valuable minds and innovative force, prohibiting the development of new technologies, these societies are blinded with nongovernmental organizations, small amount of money pulled population to the cities in order to make dependable and more obedient. Closing its markets to products from underdeveloped regions (or certain products are bought for extremely low prices) allow placement of their final products that are very expensive. Overflow of capital to developed countries and regions is performed in this way, or through interest of loans to international institutions [1,2, and 3].

Countries or regions that do not obey these rules or some countries that have managed to make better living for their own people being declared ineligible, allegedly undemocratic regime, anti-globalization, anti-civilization and so on. Global social networks and media, have great influence in the direction of facilitating such access to richer regions towards the poorer. But it can enormously be reflected as well in the opposite direction. Typical examples of population migration from poorer and conflict regions towards the economically more developed areas, i.e. towards regions where there is greater concentration of money and considerable concentration of population.

\section{POSSIBLE CONSEQUENCES OF EXTREME UNEQUAL DISTRIBUTION CAPITAL}

The consequences of the extremely uneven distribution of capital can be reflected through several aspects:

- Population migration from poorer to more developed regions (typical examples of migration from some countries in Africa and Asia to Europe, then the migration of the population of China and the Indo-Chinese Peninsula to Australia, etc.);

- Reducing productive power of less developed regions and further impoverishment;

- The problem of food supply in the hugely populated areas (China, India) will cause dislocation of population;

- The appearance of movements against a small group of people who own and concentrate capital;

- New relations between regions and countries;

- Exaggerated development of the third and quaternary activity at the expense of primary and secondary sector, productive sectors versus consumer; 
- Enormous investments in technology and automation of work processes in the economy and this would result in reduction of hiring workforce that would reflect the growing unemployment;

- Change in the habits and customs of the people (avoiding engagement in primary activities);

- Conflict between regions and equity;

- Collapse of individual states that would have high debts to the institutions and holders of capital and other aspects.

\section{DIRECTION OF EFFECTIVE USE OF MONEY}

\section{AND RESPONSE TO MORE BALANCED REGIONAL DEVELOPMENT}

The global economic development after the Second World War in terms of civilization is characterized by large technological scale in various spheres of human activities. But the pace of development in the regional was not on equal terms. Some regions whose beginnings were before the Second World War first reached the top (USA, England, France, Germany, Japan) and has maintained its pedestal, another part is little behind (Russia), the third part after the neo-colonial movement started its own development (this includes colonial countries of Africa, South America and part of Asia) today persistently fighting for greater progress, the fourth part (China, India) regions in the world their development trends of growth we achieved in these years and gradually takes the primate of the current industrialized regions, and the fifth regions that are still in the traditional socio-cultural worlds on the basis of conviction or involuntary slaves of tradition, culture and religion.

The abovementioned regional features are mutually very different in terms of population density, the presence of money, technical and technological development, employment / unemployment, living conditions (from enormous wealth to extreme poverty), militaristic problems, etc. These few and great number of other reasons cause a natural process of bidding for survival. There is mass migration from underdeveloped areas and regions to develop. On one hand, to avoid abandonment of less developed regions and on the other hand, stifling developed regions with enormous overcrowding, it is inevitable civilizational measures to be taken for a more balanced regional development. In that sense it is:

- Venture money and techniques in less developed areas so as to ensure productivity in the region (place) of residence

- Rational use of natural resources in underdeveloped regions by developed without tendencies of exploitation,

- Encouraging economic development in less developed regions through various economic and trade measures against bans purchase of products from these regions,

- Placing production technologies (in order to provide standards) from developed to less developed regions,

- Appreciating the efforts of the workforce and appropriate remuneration for providing living conditions for the family during the production year

- Deviation from militaristic tendencies which "are accidentally caused" in certain regions,

- Encouraging education systems in less developed regions and input staff assistance in technical and technological development (mean transfers from developed 
human potential in underdeveloped regions and not as it is now to buy established staff potential of less developed regions and its transfer in developed regions )

- Encourage and help to improve health services to the population,

- To take into account population policy both in developed and even more in developing countries and a number of other measures.

The before mentioned (and many other) measures are closely related to the influence of money on the development of regions and reflections that occur because of money and for money. This will ensure more equitable distribution of the world's population and the overcrowding of certain regions. Otherwise, it is expected occurrence of unpredictable processes with negative consequences in developed regions, as nature has its limitations.

\section{NEED OF CONCRETE AND MORE POWERFUL DEVELOPMENT OF GEOGRAPHY OF THE MONEYAS A SPECIAL SCIENTIFIC DISCIPLINE}

Money and its influence is a wide subject of study through economics, but space aspects are not taken into account sufficiently detailed and analytical. Basically, there is a trend of gain or loss of money and the means to fertilize the money. However, very little attention is given to the geographic concentration and distribution of money in regions around the world, its influence on development and consequences arising from it. Therefore, the need to introduce the Geography of Money as a scientific discipline (within economic geography in newer development facilities in the world) is set as a necessity. This means will not be considered only national currencies and ratios among currencies, but the impact of money on the development of the regions, the consequences and resolving development issues because of money and for money.

\section{CONCLUSION}

In the development of geographical science for different purposes there have been developed different scientific disciplines with their own subject of study. Some of them depending on the subject of study and its impact in the geographic area are more or less developed. In terms of a smaller number of population in the world and more equitable distribution of the population in the world some segments of real life were not and should not have been analysed. However, today in terms of significantly increased (and still surging trend) growth in world population and its concentration in regions (with enormous density of population) versus regional differences of economic and technological development of the concentration of money is very different. There are regions with significantly lower number of people that have substantially greater financial resources and vice versa. This causes significant changes in the geographic regions both in terms of developmental characteristics of the regions also in terms of migration of population from one region to another (mostly from underdeveloped to developed regions), but also in terms of the influence of money on the development of the regions. The influence of money is great, but how money is used, it is a matter for serious analysis through which we come to the actual change in the regions.

In this article are considered some aspects of the influence of money on the development and changes in the geographic regions where a debate is initiated as well as an access is requested in geographic analysis in terms of the geography of money as separate scientific discipline. 


\section{REFERENCES}

[1] A. Leyshon, Geography of Money and Finance I, Progress in Human Geography, 1995, 531-43.

[2] A. Leyshon, Geography of Money and Finance II, Progress in Human Geography, 1997, 381-92.

[3] A. Leyshon, Geography of Money and Finance III, Progress in Human Geography, 1998, 433-46.

[4] Gohen BJ, The Geography of Money, Ithaca, New York, Cornell University, 1998. $229 \mathrm{p}$.

[5] B. Markoski, Sopstveni regionalno geografski istrazuvanja i gledishta.

[6] http://modernsurvivalblog.com/retreat-living/survival-retreat-population-density/ 